\title{
Enciclopedia Internacional de Direito Comparado. Direito do Trabalho.
}

\author{
Antonio Ferreira Cesarino Junior \\ Professor Catedrático de Direito Social na \\ Faculdade de Direito da Universidade te \\ São Paulo.
}

Sob os auspícios da “Associação Internacional de Ciência Jurídica" está sendo prepadada uma Enciclopedia Internacional de Direito Comparado, em 16 volumes, tendo como Editor Responsável o Professor Konrad Sweigert, Diretor do "Max Planck Institut For Foreign and Comparetive Law", com sede em Hamburgo. "International Association of Legal Science", é uma organização internacional não governamental fundada sob os auspícios da Unesco, subsidiada por ela e seu órgão consultivo, assim como do Conselho Econômico e Social das Nações Unidas. O objetivo da Encyclopedia é dar um impulso essencial à comparação mundial do direito em geral e ao mesmo tempo ajudar a realizar as suas numerosas práticas.

Resumiremos aqui as comunicações feitas a respeito, pela "Associação", assim como duas notícias do "The American Journal of Comparative Law", publicado em "Ann Arbor", pela Associação Americana para o Estado Comparativo do Direito (Vol. 14, n. 1, ns. 211/2 e vol. 15, ns. 1.2, ps. 412/5). 
A enciclopedia se dirige em primeiro lugar aos legisladores nacionais e internacionais e depois ao mundo acadêmico. Aos legisladores a Enciclopedia deseja oferecer modêlos para a solução de importantes problemas legais de relevância atual, que ajudariam os legisladores dos paises desenvolvidos a melhorar a legislação e auxiliariam os juízes no desenvolvimento do direito estatutário e jurisprudencial. Para os países em desenvolvimento ajudará os esforços para a codificação, como fonte de informações, de idéias e de experiência. Do ponto de vista acadêmico, será útil instrumento para o ensino do direito comparado, apresentando as mais importantes soluções típicas dos ordenamentos jurídicos de todo o mundo. Não terá uma divisão geográfica, a não ser no primeiro dos 16 volumes (National Reports), com breves descrições de cada sistema legal. Os outros 16 são dedicados à comparação, com informações sôbre as soluções divergentes dos problemas jurídicos. Para cada problema sòmente as soluções típicas serão descritas em pormenores pelo recurso ao sistema legal que mais característicamente a adota, com breves referências a outros países que sigam essencialmente a mesma solução. Após sua apresentação e análise, haverá uma crítica comparativa e sugestões para o aperfeiçoamento.

Para a realização dêste projeto o Comité Internacional de Direito Comparado, que é a comissão executiva da Associação Internacional de Ciência Jurídica, estabeleceu uma comissão especial para a Encyclopedia composta dos Srs. Angel, Lipstein, Van Menhren, Remikanen, Nozmarin, Tunc e Prof. Konrad Zweigert, êste último designado seu "Editor Responsável", tendo o Dr. Ulrich Drobning como "Secretário Executivo". Cada volume, de cêrca de 1000 páginas, em formato de dicionário, tem um "Editor-Chefe."

O do volume XIV, consagrado ao Direito do Trabalho (Labour Law) é o Professor OtTo KAHN-FrevND, da Universidade de Oxford, na Inglaterra. Cada editor-chefe é assessorado por um Conselho Consultivo, no qual estão repre- 
sentados todos os grandes sisternas de Direito e com êle dispõe o plano para o seu volume. A seguir escolhe os "Relatores-Gerais para cada capítulo, cada um dos quais assume a responsabilidade definitiva, podendo recorrer a consultores nacionais para questões referentes ao seu direito pátrio. Os projetos de todos os relatores gerais serão lidos e discutidos pelo Conselho Consultivo de cada volume. A Enciclopédia será publicada em inglês, sendo estabelecida uma terminologia uniforme, tendo em conta as diferenças do inglês britânico e americano.

É o seguinte o Conselho Consultivo do Vol. XIV (Labour Law) : Prof. Camerlynck (Paris), Prof. Cesarino (São Paulo), Dr. Jenks (Genebra), Prof. Riesenfeld (Berkeley), Prof. Schmidt (Stockholm), Prof. Summers (New Haven), Prof. Szubert (Lodz).

São os seguintes os capítulos com os respectivos Relatores Gerais: 1. Sources of Labour Law. National and International Legal and Non-Legal Sources of Norm and Sanctions; a International Sources - C. F. Jenks, Genebra; b National Sources - Prof. KAHN- Freund, Oxford; 2. Scope of Labour Law as regards Persons and Subject-Matter. Categories of Employees and their Relevance - Prof. Giugni, Roma; 3. Making, Modification and Termination of Employment Relationships and the Obligations resulting from such Relationships in General - Prof. Camerlynck, Paris; 4. Wages and Remuneration in General. The Determination of Wage Rates, Forms of Wages, Methods of Payment, Protection of Wages, Holidays with Pay, Pensions and other Fring Benefits - Prof. Weltner, Budapest; 5. Hours of Work. Weekly Rest. The Employment of Protected Persons - Prof. Cesarino JR., São Paulo; 6. Health, Safety and Welfare - Prof. Szubert, Lodz; 7. Accidents at Work and Occupational Diseases.; a) Private Law - Prof. FleMING; b. Social Insurance - Prof. Dupeyroux, Paris; 8. Labour Market Regulation. Man-power Policy, Employment Services, Vocational Training (incl. Apprenticeship), Equa- 
lity of Treatment in Employment and Occupation. Unemployment Insurance -- Prof. Blanpain, Louvain; 9. Trade Unions and Employers' Associations - Prof. Summers, New Haven/USA; 10. Collective Bargaining and Collective Agreements - Prof. ScHмidT, Stockholm; 11. Representation of the Employees at Plant and Enterprise Level - Prof. Gamillscheg - Göttingen; 12. Prevention and Settlement of Labour Disputes, other than Conflicts of Right - Mr. Givry, Genebra; 13. Strikes, Lockouts and other Hostile Actions Prof. Simitis Giessen; 14. Organization, Jurisdiction, Composition and Procedure of Labour Courts, and of Organs of Arbitration for the Settlement of Grievances Arising from Existing Contracts of Employment, Collective Agreement, and Plant Agreement - Prof. Aaron, Los Angeles; 15 Organization and Functioning of Administrative Authorities Concerned with Labour Problems, incl. Organs. of Inspection and Enforcement - Prof. Yamaguchi, Tokyo. 